\title{
Conflitos na gestão de recursos hídricos no Estado de Minas Gerais: Estudo de caso da Bacia Hidrográfica do córrego dos Quatis, Itueta - Minas Gerais, Brasil
}

Conflicts in the management of water resources in the State of Minas Gerais: Case sstudy of the

Quatis stream, Itueta - Minas Gerais, Brasil

Conflictos en la gestión de los recursos hídricos en el Estado de Minas Gerais: Estudio de caso en la Cuenca Hidrográfica del arroyo Quatis, Itueta - Minas Gerais, Brasil

Hilda Fabiana Moura Marques

ORCID: https://orcid.org/0000-0001-5881-4929 Universidade Federal de Itajubá, Brasil E-mail: hildafabiana@unifei.edu.br

Barbara Carolina Reis

ORCID: https://orcid.org/0000-0002-9549-735X Universidade Federal de Itajubá, Brasil E-mail: barbaracreis@unifei.edu.br Vitor Soares Feitoza

ORCID: https://orcid.org/0000-0003-1365-687X Universidade Federal de Itajubá, Brasil E-mail: vitorfeitoza.eng@gmail.com José Geraldo da Silva

ORCID: https://orcid.org/0000-0002-9284-6374 Universidade Federal de Itajubá, Brasil E-mail: geraldoesa@unifei.edu

Roberto Cézar de Almeida Monte-Mor

ORCID: https://orcid.org/0000-0003-3158-6967 Universidade Federal de Itajubá, Brasil E-mail: rmontemor@unifei.edu.br

\begin{abstract}
Resumo
O presente artigo realizou uma análise técnica sobre uma área declarada de conflitos pelos usos de recursos hídricos, na bacia hidrográfica do córrego dos Quatis, localizada no município de Itueta, Minas Gerais e teve como principal objetivo analisar o conflito pelo uso da água identificado no local. A pesquisa foi embasada no documento de Análise de Conflito pelo Uso da Água (ACUA) nº 01/2019, cedido pelo Instituto Mineiro de Gestão das Águas (IGAM), com informações relativas a usuários outorgados e de usos insignificantes, vazões da bacia, relações demanda $\mathrm{x}$ disponibilidade, e mapa de uso e ocupação do solo. Os resultados obtidos pelo ACUA retornaram valores de déficit hídrico na relação demanda x disponibilidade, além de estarem apoiados no mapa de uso e ocupação do solo com usos voltados principalmente a irrigação; e as soluções encontradas para o conflito ficaram relacionadas à instituição de uma Comissão Gestora Local e a elaboração do termo de alocação de água para a outorga coletiva. Por fim, além das soluções apontadas para minimizar ou resolver o conflito, foram indicadas outras iniciativas relacionadas a projetos ambientais para aumentar o potencial hídrico da região.
\end{abstract}

Palavras-chave: Conflito pelo uso da água; Outorga coletiva; Déficit hídrico.

\begin{abstract}
The present article carried out a technical analysis on an area declared of conflicts for the use of water resources, in the hydrographic basin of Quatis stream, located in the municipality of Itueta, Minas Gerais, and had as main objective to analyze the conflict for the use of water identified in the place. The research was based on the Conflict Analysis for Water Use (ACUA) document 01/2019, provided by the Mineiro Institute of Water Management (IGAM), with information related to users granted and of insignificant uses, flows from the basin, relationships demand $x$ availability, and land use and occupation map. The results obtained by ACUA returned water deficit values in the demand $\mathrm{x}$ availability ratio, in addition to being supported by the map of land use and occupation with uses mainly aimed at irrigation; and the solutions found for the conflict were related to the establishment of a Local Management Commission and the elaboration of the water allocation term for collective award. Finally, in addition to the solutions aimed at minimizing or resolving the conflict, other initiatives related to environmental projects to increase the region's water potential were indicated.
\end{abstract}


Keywords: Conflict over water use; Collective grant; Water deficit.

\section{Resumen}

El presente artículo realizó un análisis técnico sobre un área declarada de conflictos por el uso de los recursos hídricos, en la cuenca hidrográfica del arroyo Quatis, ubicada en el municipio de Itueta, Minas Gerais y tuvo como objetivo principal analizar el conflicto por uso de agua identificado en el lugar. La investigación se basó en el documento Análisis de Conflictos por Uso del Agua (ACUA) 01/2019, proporcionado por el Instituto Mineiro de Gestión del Agua (IGAM), con información relacionada con usuarios otorgados y de usos insignificantes, caudales de la cuenca, relaciones demanda x disponibilidad, y mapa de uso y ocupación del suelo. Los resultados obtenidos por ACUA arrojaron valores de déficit hídrico en la relación demanda x disponibilidad, además de estar respaldados por el mapa de uso y ocupación del suelo con usos principalmente orientados al riego; y las soluciones encontradas al conflicto estuvieron relacionadas con la institución de una Comisión de Gestión Local y la elaboración del plazo de asignación de agua para el subsidio colectivo. Finalmente, además de las soluciones orientadas a minimizar o resolver el conflicto, se señalaron otras iniciativas relacionadas con proyectos ambientales para incrementar el potencial hídrico de la región.

Palabras clave: Conflicto por uso del agua; Subvenciones colectivas; Déficit hídrico.

\section{Introdução}

Considerando a importância da água e sua essencialidade para a manutenção das atividades das sociedades modernas, ressalta-se que, em virtude principalmente da sua dinâmica espacial e temporal, a mesma, vem sendo cerne de conflitos, os quais têm sido cada vez mais frequentes e intensos em nosso país. Bem como os supracitados, o aumento do uso da água, influenciado pelo crescimento populacional e industrial, ou ainda, a inexistência e inadequação de medidas de gestão hídrica são fatores que também podem inferir o surgimento de conflitos, realçando a necessidade do estabelecimento de mecanismos proativos que possam minimizá-los ou solucioná-los (Varella, 2012; Amorim, Ribeiro \& Braga, 2016).

No Brasil, a Política Nacional de Recursos Hídricos, Lei n 9.433, de 8 de janeiro de 1997 se constitui o dispositivo legal que visa a regulamentação e gestão dos recursos hídricos (Brasil, 1997). Em síntese, ela estabelece como instrumentos de gestão, a outorga de direito de uso dos recursos hídricos, o enquadramento dos corpos d'água, a cobrança pelo uso da água, entre outros, além de definir como um de seus fundamentos, uma gestão descentralizada e participativa, colegiada, por meio dos Comitês de bacias hidrográficas e diversos outros entes do sistema.

Conforme previsto pela Política Nacional de Recursos Hídricos, a gestão dos recursos hídricos possui como unidade básica de gestão, a bacia hidrográfica. Tal divisão se faz necessária devido a garantia oferecida de um planejamento integrado e coerente ao longo de todo o corpo d'água. Dessa forma, considerando que o agravamento das disputas pelo uso da água pode aflorar em conflitos nesses territórios, o estabelecimento da bacia hidrográfica como unidade físico-territorial de gestão dos recursos hídricos permite equacionar problemas comuns além de contribuir positivamente para a tomada de decisões.

Quanto ao estado de Minas Gerais, a Política Estadual de Recursos Hídricos foi instituída pela Lei n o 13.199, de 29 de janeiro de 1999, tendo como um de seus fundamentos, assegurar o controle, pelos usuários atuais e futuros, do uso da água e de sua utilização em quantidade, qualidade e regime satisfatórios (Minas Gerais, 1999). Todavia, segundo Costa (2019), eventualmente, os problemas de conflitos têm se agravado no estado nos últimos anos, graças ao uso mais intensivo ou ainda, devido a alterações no ciclo hidrológico. $\mathrm{O}$ autor aduz ainda que, diversas bacias hidrográficas localizadas no estado de Minas Gerais não conseguem atender todas as demandas, as quais costumavam atender, em virtude das baixas vazões e aumento do uso de água.

Tendo em visto o exposto, pontua-se que o objetivo deste artigo compreende uma análise crítica sobre o conflito pelos usos de recursos hídricos, instaurado na bacia hidrográfica do Córrego dos Quatis, município de Itueta/MG. À luz da legislação brasileira serão identificados os envolvidos no conflito, a relação entre o uso e ocupação do solo com os usuários dos recursos hídricos, de forma a expor as raízes do problema na bacia. E, finalmente, com base nestas informações pretende-se avaliar possíveis soluções a serem tomadas de forma subsidiária à realidade da situação. 


\section{Metodologia}

Sob o ponto de vista teórico - metodológico, a pesquisa se classifica como qualitativa. O trabalho foi desenvolvido por meio de um estudo de caso localizado no município de Itueta/MG, na bacia hidrográfica denominada córrego dos Quatis. Para a realização da pesquisa procedeu-se um extenso levantamento de dados das legislações pertinentes sobre o tema, bem como a fundamentação técnica através da documentação de Análise de Conflito pelo Uso da Água - ACUA 01/2019, emitida pelo órgão gestor estadual de recursos hídricos, o Instituto Mineiro de Gestão das Águas (IGAM).

Ademais, realizou-se ainda, a tabulação das informações referentes ao universo de estudo, como os principais tipos de uso de recurso hídrico e disponibilidade hídrica, de forma a realizar uma consonância com mapa de uso e ocupação do solo. Além de realizar essa caracterização dos usuários, fez-se uma avaliação e levantamento das possíveis alternativas baseadas em mecanismos de resolução de conflitos em bacias, conforme a legislação brasileira de recursos hídricos.

Para confecção do mapa de uso e ocupação do solo foi utilizado o plugin Semi Classification Plugin (SCP) acoplado ao software QGis 3.8, tendo como base 1 cena do satélite Sentinel 2 com resolução espacial de 10 metros, baixada via site Earth Explorer do Serviço Geológico dos Estados Unidos (USGS, 2020).

\section{1 Área de estudo}

Compreende a área de estudo, o território da Bacia Hidrográfica do córrego dos Quatis, localizada no município de Itueta em Minas Gerais possui área aproximada de 75,85 km² e está inserida integralmente na cidade de Itueta, incluindo a área urbana do município, tal qual representado na Figura 1.

Figura 1 - Mapa de Localização da Bacia Hidrográfica do córrego dos Quatis.
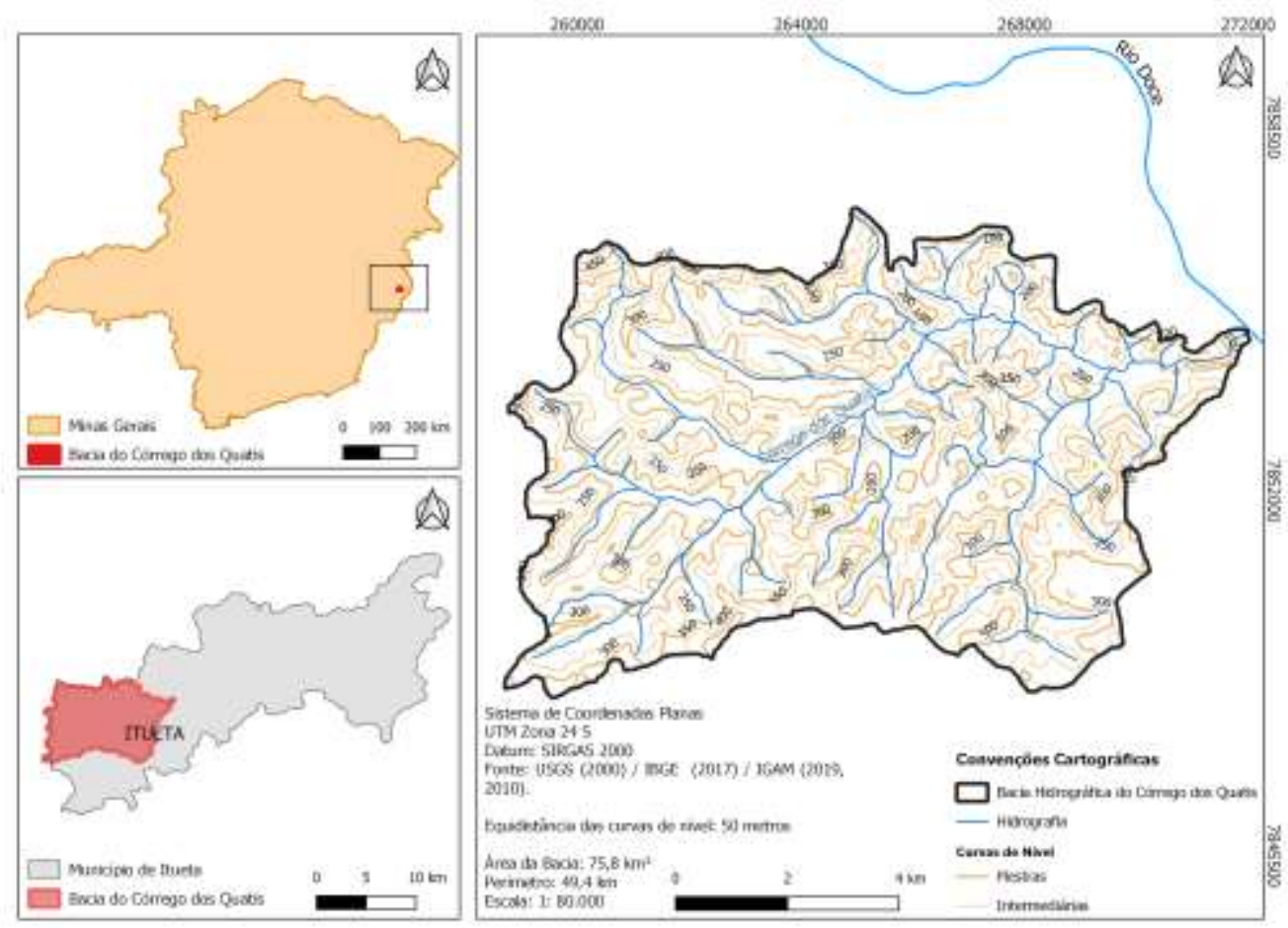

Fonte: Autores (2020).

A bacia hidrográfica do córrego dos Quatis está localizada na cidade de Itueta no estado de Minas Gerais. O referido córrego é um afluente direto da margem esquerda rio Doce, pertencente à Unidade de Planejamento e Gestão dos Recursos Hídricos (UPGH D06) do rio Manhuaçu. 


\subsection{Aspectos legais e sociais}

A outorga do direito de uso de recursos hídricos é um dos cinco instrumentos de gestão que foram instituídos pela Política de Recursos Hídricos, sendo a responsável por assegurar o controle quantitativo e qualitativo dos usos da água, bem como garantir o efeito exercício dos direitos de acesso à água. Este ato administrativo é publicado no Diário Oficial da União (no caso da ANA), ou nos Diários Oficiais dos Estados ou do Distrito Federal (Brasil, 1997).

Neste sentido, a outorga deve ser vista como instrumento de alocação de água no interior de uma bacia hidrográfica, considerando os mais diversos usos existentes no local. Para que seja utilizada como ferramenta de articulação da gestão dos recursos hídricos, deve atender a diversos preceitos, como: o atendimento das necessidades ambientais, econômicas e sociais por água, redução ou eliminação dos conflitos entre usuários, e possibilidade de atender demandas futuras da região que for instaurada (ANA, 2011a).

De acordo com a ANA (2011b), para realizar tais funções, pode ser estabelecido a criação de um Comitê de bacia hidrográfica, que se constitui como um órgão colegiado com funções deliberativas, normativas e consultivas. Esse organismo tripartite possui representações do Poder Público, usuários e sociedade civil, sendo utilizado como espaço para estabelecer regras e arbitrar solução de conflitos em primeira instância.

Esses processos de resolução de conflitos, iniciados através dos plenários dos Comitês de bacia, esbarram em complexidades do ponto de vista político e institucional como principais obstáculos para alcançar o objetivo de acesso a todos os usuários. Porém, ao criar esse âmbito de gestão descentralizada, tornando-o mais democrático com a articulação entre comitê e usuários, o processo de gerenciamento tem mais chances de ser eficaz e com maior efetividade econômica, política e social (Orosco, 2018).

\section{Resultados e Discussão}

\subsection{O conflito}

O conflito pelo uso de recursos hídricos se instaura quando em determinada bacia a demanda pelo uso da água por seus usuários superficiais for maior do que o limite outorgável a fio d'água. Neste sentido, foi publicada a portaria do IGAM de $\mathrm{n}^{\circ} 15$ de 04 de abril de 2019 que estabeleceu por meio do Art. 1 a Declaração de Área de Conflito - DAC n 001/2019 para a sub-bacia hidrográfica do córrego dos Quatis, no município de Itueta/MG. Para instauração do conflito considerou-se o Inquérito Civil $\mathrm{n}^{\circ}$ MPMG - 0543.16.000060-9 da Promotoria de Justiça da Comarca de Resplendor que investiga as irregularidades na captação e represamento de águas no córrego Quatis, município de Itueta/MG.

Para o cálculo da disponibilidade hídrica na bacia e definição da quantidade máxima a ser distribuída entre os usuários, o IGAM utiliza-se de dados obtidos do Sistema Integrado de Informação Ambiental (SIAM) e do "Estudo de regionalização de Vazão para aprimoramento do processo de outorga no Estado de Minas Gerais", de 2012. Ainda, segundo a Portaria IGAM n 48 de 04 de outubro de 2019, as bacias com DAC deverão ser garantidas um fluxo residual mínimo equivalente a $50 \%$ (cinquenta por cento) da Q7,10 com vistas atenuar os conflitos existentes.

Como citado acima, os dados de disponibilidade hídrica são obtidos por 2 fontes sendo realizados pelo ACUA 01/2019 para embasar a análise, conforme é apresentado no Quadro 1: 
Quadro 1 - Disponibilidade hídrica da bacia do córrego dos Quatis.

\begin{tabular}{|c|c|c|}
\hline Dados & SIAM & Regionalização de Vazão \\
\hline Área de drenagem & $75,85 \mathrm{~km}^{2}$ & $76,18 \mathrm{~km}^{2}$ \\
\hline $\operatorname{Re}_{\min }$ & $0,25 \mathrm{~L} / \mathrm{s}^{*} \mathrm{~km}^{2}$ & - \\
\hline $\mathrm{Q}_{7,10}$ & $17,0653 \mathrm{~L} / \mathrm{s} \mathrm{ou} 0,01707$ & $35,11 \mathrm{~L} / \mathrm{s} \mathrm{ou} 0,03511 \mathrm{~m}^{3} / \mathrm{s}$ \\
\hline $50 \% \mathrm{Q}_{7,10}$ & $8,533 \mathrm{~L} / \mathrm{s} \mathrm{ou} 0,00853 \mathrm{~m}^{3} / \mathrm{s}$ & $17,56 \mathrm{~L} / \mathrm{s} \mathrm{ou} 0,01756 \mathrm{~m}^{3} / \mathrm{s}$ \\
\hline
\end{tabular}

Fonte: Minas Gerais (2019).

Diante do exposto percebe-se que a bacia do córrego dos Quatis apresenta baixa disponibilidade hídrica com valor outorgável de 8,533 L/s, os fatores que interferem nesse resultado é uma área de drenagem pequena e rendimento específico baixo.

Enquanto isso, a relação entre a demanda e a disponibilidade hídrica da bacia também são de suma importância, por isso também foram levantados todos os usos, conforme Quadro 2:

Quadro 2 - Demanda dos usuários cadastrados na bacia.

\begin{tabular}{|c|c|c|c|}
\hline Tipo de cadastro & Quantidade & Totais & Demanda $\left(\mathrm{m}^{3} / \mathrm{s}\right)$ \\
\hline Cadastros de uso insignificante vigentes & 43 & \multirow{3}{*}{47} & \multirow{3}{*}{0,04992} \\
\hline $\begin{array}{c}\text { Outorgas vigentes consuntivas (deferidas e } \\
\text { renovadas) }\end{array}$ & 3 & & \\
\hline Outorga vigente deferida não consuntiva & 1 & & \\
\hline Cadastros de uso insignificante vencidos & 53 & \multirow{4}{*}{64} & \multirow{4}{*}{-} \\
\hline Outorga vencida & 1 & & \\
\hline $\begin{array}{l}\text { Outorgas indeferidas por indisponibilidade } \\
\text { hídrica }\end{array}$ & 6 & & \\
\hline Processos em análise técnica & 4 & & \\
\hline
\end{tabular}

Fonte: Minas Gerais (2019).

Os cadastros vigentes na bacia têm uma demanda de água 0,04992 m³/s, observa-se que do total de 47 cadastros vigentes 43 são cadastros de uso insignificante ou seja são aquelas captações com vazão inferior a $1 \mathrm{~L} / \mathrm{s}$.

\subsection{Relação entre uso do solo e usos dos recursos hídricos}

A relação entre o uso e ocupação do solo e os usos de recursos hídricos está intrinsecamente ligada, pois vislumbra-se uma maior ou menor utilização destes, de acordo com os usos preponderantes na bacia hidrográfica. A Figura 2 representa os principais usos e ocupação do solo na área de estudo. 
Figura 2 - Mapa de Uso e Ocupação do Solo da Bacia do córrego dos Quatis.

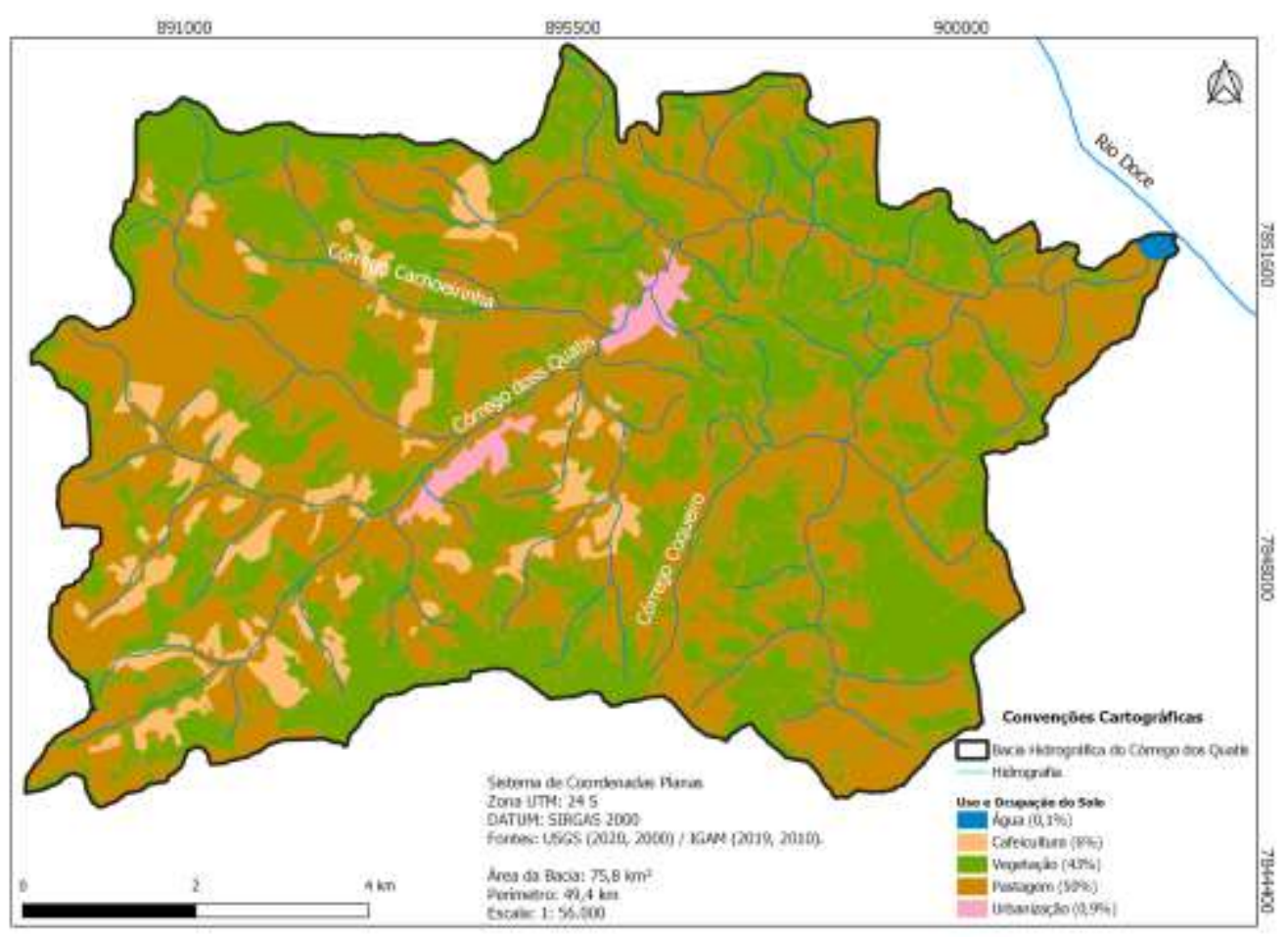

Fonte: Autores (2020).

$\mathrm{Na}$ bacia do córrego dos Quatis são observados os seguintes usos do solo: pastagem (50\%), vegetação (43\%), cafeicultura (6\%), duas parcelas urbanas referentes à sede do município e ao distrito de Quatitubá $(0,9 \%)$ e uma pequena porção do rio Doce na foz da bacia $(0,1 \%)$.

De acordo com o ACUA 01/2019 do córrego dos Quatis, atualmente, as outorgas deferidas são para abastecimento público e irrigação, com retirada de $0,0180 \mathrm{~m}^{3} / \mathrm{s}$ do corpo hídrico; além destes, observa-se um valor consuntivo de 0,03192 $\mathrm{m}^{3} / \mathrm{s}$ pelos usos insignificantes. Também são observadas outras outorgas com o objetivo de irrigação que sofreram indeferimento devido à indisponibilidade hídrica, provavelmente um dos motivos substanciais para o início dos conflitos pelo uso da água na região da bacia.

Os demais cadastros de uso insignificante estão associados em sua grande maioria ao processo de irrigação e a dessedentação de animais, o que vai ao encontro com o uso do solo destinado a pecuária através das pastagens irrigadas. Esses cadastros juntamente às outorgas deferidas são parâmetros de controle para novas outorgas, e, portanto, são de suma importância para a plena governança do Comitê de Bacia Hidrográfica da região.

Tendo em vista que o critério de outorga estabelece restrições à expansão de determinado uso em uma bacia hidrográfica, também se pode inferir que haverá forte correlação no desenvolvimento econômico e social da região. Devido a isso, a observância dos Planos de recursos hídricos quanto à disponibilidade hídrica, aos usos preponderantes e às metas que desejam serem alcançadas na bacia devem ser utilizados como parâmetros para o deferimento de novas outorgas.

\subsection{Avaliação do conflito}

De acordo com os dados do parecer técnico do ACUA 01/2019, a referida bacia de estudo foi alvo de denúncias de conflitos pelo uso da água e passou por fiscalização e atuação do Ministério Público de Minas Gerais. O parecer do Ministério Público consta a orientação para a emissão da DAC relativa à sub-bacia do córrego dos Quatis, de modo que os envolvidos 
sejam regularizados por meio de processo administrativo de Outorga Coletiva e todos os usuários possam ter acesso ao recurso hídrico, desde os usuários mais a montante quanto aos da jusante.

Como foi observado nos resultados da análise do conflito, citadas nos tópicos anteriores, as demandas dos usuários são superiores a disponibilidade hídrica da bacia. De porte do ACUA 01/2019 foram somadas todas as vazões outorgadas vigentes e os usos insignificantes cadastrados na bacia, e constatou-se a utilização de $0,04992 \mathrm{~m}^{3} / \mathrm{s}$ a fio d'água no córrego dos Quatis.

Tendo em vista essa carência, os dados do SIAM trazem a seguinte razão: $0,04992 \mathrm{~m} 3 / \mathrm{s}>0,00853 \mathrm{~m} / \mathrm{s}$; enquanto os resultados do Estudo da Regionalização de Vazão demonstram os seguintes valores: 0,04992 m³/s >0,01756 m³/s. A partir desses valores, nota-se como o rendimento máximo hídrico a ser utilizado não foi respeitado e, portanto, apresentou déficit nos dois possíveis estudos de Demanda X Disponibilidade.

\subsection{Possíveis Soluções do Conflito}

Uma das soluções técnicas apresentadas pelo Ministério Público para solucionar o problema na bacia, e que não foi eficiente devido ao grande número de usuários foi a utilização de água subterrânea em poços manuais com bombeamento até reservatórios de acumulação superficial fora do curso d'água para armazenamento, que posteriormente seria bombeada para sistema de irrigação de plantações. Outra proposta seria a construção de barragens junto ao córrego, com reservatórios para armazenamento de águas no período chuvoso, o que seria do ponto de vista técnico suficiente para o abastecimento no período de seca, caso houvesse necessidade captação de águas subterrâneas em poços manuais profundos.

As soluções de conflitos pelo uso dos recursos hídricos em Minas Gerais são regidas pelo Decreto № 47.705 de 04/09/2019 onde o mesmo estabelece que os comitês de bacia terão atuação nessas áreas convocando os usuários para a criação de uma proposta de alocação negociada do recurso hídrico, onde será gerado um processo único de outorga de coletiva com o apoio do IGAM. Segundo o IGAM (2020), a outorga coletiva é um instrumento que prevê uma autorização única para todos os usuários de uma área em que houve a Declaração de Área de Conflito.

Atualmente, o IGAM instituiu a Comissão Gestora Local - CGL no âmbito do processo de outorga coletiva de direito de uso de recursos hídricos superficiais em áreas declaradas de conflito pelo uso dos recursos hídricos, através da Portaria IGAM $n^{\circ} 26$, de 05 de junho de 2020. O objetivo da CGL é aumentar a gestão participativa do uso das águas e diminuir conflitos pelo uso dos recursos hídricos onde a demanda por água é maior que a disponibilidade. Por meio dessa portaria, os próprios usuários que possuíam outorga vigente antes da declaração de área de conflito definirão, entre eles, as condições para que cada um faça parte de uma mesma outorga coletiva.

Neste sentido, a CGL deverá elaborar o termo de alocação de água da bacia com conflitos, de forma a perseguir diversos objetivos, conforme descrito na Instrução Normativa n 03/2020 do IGAM (Minas Gerais, 2020): i) A distribuição de recursos hídricos entre os usuários existentes em uma porção hidrográfica; ii) A garantia do princípio dos usos múltiplos; iii) $\mathrm{O}$ atendimento das necessidades ambientais e sociais por recursos hídricos; iv) A eliminação ou a atenuação dos conflitos entre usuários dos recursos hídricos; v) O planejamento das demandas hídricas futuras.

\section{Considerações Finais}

A indisponibilidade hídrica evidenciada através do documento de análise do IGAM, tem sido o motivo de indeferimento de diversas outorgas de direito de uso na região, por isso, salienta-se como a falta de fiscalização somada à crescente necessidade de recursos hídricos nos meios produtivos, essencialmente quanto à irrigação, podem resultar no aumento de conflitos na bacia hidrográfica do córrego dos Quatis. 
A utilização de uma Comissão Gestora Local poderá ser um diferencial para a solução na gestão de conflitos de recursos hídricos, pois traz os preceitos estabelecidos na Lei das Águas, quanto à subsidiariedade. O termo de alocação de água poderá ser um marco na gestão das águas da bacia do córrego dos Quatis, pois assegurará os usos múltiplos, atenderá as necessidades ambientais, além de ter como base o planejamento das demandas futuras para a região. Poderá ser considerado um marco na regulação assim como é visto nas Comissões Gestoras de Açudes no Estado do Ceará - CGA/CE (ANA, 2011b), referências na alocação negociada de águas.

Além desses procedimentos, destacam-se outras atividades de cunho técnico cabíveis à região, como a execução de projetos de proteção aos mananciais, projetos nas áreas de recarga, incentivo aos produtores de água (detentores de nascentes), pois somente com a imersão nestes valores poder-se-á minimizar ou resolver o problema de conflito, que é gerando a fonte do problema, a água.

Com os dados levantados no estudo percebe-se alta demanda de captações de água ditas como usos insignificantes, diante disso, espera-se que o presente trabalho contribua para melhor gerenciamento de recursos hídricos no local, possibilitando melhor distribuição de água entre os usuários.

\section{Agradecimentos}

Os autores agradecem à Universidade Federal de Itajubá - UNIFEI, à Agência Nacional de Recursos Hídricos - ANA, à Coordenação de Aperfeiçoamento de Pessoal de Nível Superior - CAPES e ao Programa de Mestrado Profissional em Rede Nacional em Gestão e Regulação dos Recursos Hídricos - ProfÁgua, projeto CAPES/ANA.

\section{Referências}

Amorim, A. L., Ribeiro, M. M. R. \& Braga, C. F. C. (2016). Conflitos em bacias hidrográficas compartilhadas: o caso da bacia do rio Piranhas-Açu/PB-RN. Revista RBRH, 21 (1), 36 - 45.

Agência Nacional de Águas - ANA. (2011a). Outorga de direito de uso de recursos hídricos. Cadernos de Capacitação em recursos hídricos, Brasília.

Agência Nacional de Águas - ANA. (2011b). Alternativas Organizacionais para gestão de recursos hídricos. Cadernos de Capacitação em recursos hídricos. Brasília.

Brasil. Lei $n^{\circ} 9.433$ de 8 de Janeiro de 1997. Lei dos Recursos Hídricos. Institui a Política Nacional de Recursos Hídricos, cria o Sistema Nacional de Gerenciamento de Recursos Hídricos, regulamenta o inciso XIX do art. 21 da Constituição.

Costa, P. G. (2019). Subsídios para a resolução de conflito pelo uso dos recursos hídricos: o caso da Bacia Hidrográfica do Ribeiro Bonito, em Caeté - MG. Dissertação (Tecnologias e Inovações Ambientais). Universidade Federal de Lavras, Lavras, Minas Gerais.

Instituto Mineiro de Gestão das Águas - IGAM. (2020). Dúvidas sobre outorga coletiva. <http://www.igam.mg.gov.br/banco-de-noticias/2381-igam-vaipromover-webinar-para-tirar-duvidassobreoutorgacoletiva>

IGAM. (2020). Portaria IGAM N $N^{o}$, de 05 de Junho de 2020. Institui a Comissão Gestora Local - CGL - no âmbito do processo de outorga coletiva de direito de uso de recursos hídricos superficiais em áreas declaradas de conflito pelo uso dos recursos hídricos. Diário Oficial de Minas Gerais, Diário do Executivo, Belo Horizonte.

Minas Gerais. (2020). Instrução Normativa 03/2020. Procedimentos para Regularização dos Usos de Recursos Hídricos de Minas Gerais - Outorga Coletiva. Belo Horizonte.

Minas Gerais. (2019). Decreto $N^{o} 47705$ de 04 de setembro de 2019. Estabelece normas e procedimentos para a regularização de uso de recursos hídricos de domínio do Estado de Minas Gerais. Diário Oficial de Minas Gerais, Diário Executivo, Belo Horizonte.

Minas Gerais. (2019). Portaria IGAM No 48, de 04 de Outubro de 2019. Estabelece normas suplementares para a regularização dos recursos hídricos de domínio do Estado de Minas Gerais e dá outras providências. Diário Oficial de Minas Gerais, Diário do Executivo, Belo Horizonte.

Minas Gerais. (2019). Portaria IGAM N $N^{o}$, de 04 de Abril de 2019. Institui a Comissão Gestora Local - CGL - no âmbito do processo de outorga coletiva de direito de uso de recursos hídricos superficiais em áreas declaradas de conflito pelo uso dos recursos hídricos. Diário Oficial de Minas Gerais, Diário do Executivo, Belo Horizonte.

Instituto Mineiro de Gestão das Águas - IGAM. (2019). Análise de Conflito pelo uso da água -ACUAA 01/2019: bacia do córrego dos Quatis, município de Itueta/MG, 32p.

Minas Gerais. (1999). Lei n 13.199, de 29 de janeiro de 1999. Dispõe sobre a Política Estadual de Recursos Hídricos e dá outras providências. 
Research, Society and Development, v. 10, n. 1, e27910111967, 2021

(CC BY 4.0) | ISSN 2525-3409 | DOI: http://dx.doi.org/10.33448/rsd-v10i1.11967

Orosco, R. T. (2018). Conflitos na gestão de recursos hídricos no Brasil: O caso da interligação Jaguari-Atibainha na bacia hidrográfica do rio Paraíba do Sul. III Simpósio de Recursos Hídricos da bacia do rio Paraíba do Sul, Juiz de Fora, 1-10.

Serviço Geológico dos Estados Unidos -USGS. (2020). Programa Copernicus da Agência Espacial Europeia (2020).

Varella, J. S. (2012). A essencialidade da água frente ao direito de propriedade e a Constituição Federal de 1988. In: Os recursos naturais e o homem: o direito ao meio ambiente ecologicamente equilibrado frente à responsabilidade solidária. Butzke, Alindo \& Pontalti, Sieli. (Org.). Dados eletrônicos, Caxias do Sul, RS: Educs, 123-137. 